\title{
HUMOR DALAM PERUMPAMAAN \\ TENTANG PENGAMPUNAN \\ (MATIUS 18:21-35)
}

\section{Stefanus Kristianto}

Abstrak: Disadari atau tidak, untuk rentang waktu yang lama, sebenarnya ada tendensi anti-humor yang kuat dalam Kekristenan. Hal ini tidak mengejutkan sebab tradisi Kristen memang telah mewariskan semacam sentimen negatif terhadap humor. Dalam studi ini, penulis akan mencoba meresponi salah satu dampak negatif dari tradisi ini, yaitu pengabaian atau penolakan terhadap eksistensi humor dalam Alkitab. Lebih spesifiknya, penulis akan mencoba menunjukkan potensi humor dalam sebuah teks, yakni perumpamaan tentang pengampunan (Matius 18:21-35). Untuk mencapai hal tersebut, penulis akan lebih dulu berusaha memberikan definisi provisional tentang humor. Setelah itu, penulis akan membahas konteks dan konten dari perikop tersebut, sebelum pada akhirnya memaparkan beberapa usulan mengenai humor dalam teks tersebut.

Kata-kata kunci: Humor, Injil Matius, Perumpamaan, Pengampunan, Keganjilan, Hyperbola

Abstract: Whether it is realized or not, for a long period of time, there has been a strong anti-humor tendency within the church. This is not surprising since the Christian tradition has indeed bequeathed a kind of negative sentiment toward humor. In this study, the writer is trying to respond to one of the negative impacts of this tradition, namely the ignorance or the denial of the existence of humor in the Bible. Specifically, the writer will try to show humor potentials in a certain passage of the Bible, i.e. the parable of the Unmerciful Servant (Matthew 18:21-35). To achieve the goal, the writer will first attempt to give a provisional definition of 
humor. Afterwards, he will discuss the context and content of the passage, and finally, he will discuss some suggestions as to humor in the passage.

Keywords: Humor, the Gospel of Matthew, Parables, Unmerciful Servant, Incongruity, Hyperbole

\section{PENDAHULUAN: TRADISI YANG ANTI-HUMOR}

Beberapa tahun yang lampau, dalam sebuah seminar, salah seorang mentor penulis pernah mengisahkan pengalamannya ketika dia mulai belajar berkhotbah di sebuah sekolah teologi. Dia menceritakan bahwa salah seorang dosennya pernah menegurnya, karena dia kerap menghadirkan gurauan-gurauan dalam khotbahkhotbahnya. Bagi dosen tersebut, khotbah dan mimbar adalah hal yang kudus dan, oleh sebab itu, tidak sepatutnya "dikotori" atau "dinajiskan" dengan berbagai gurauan. ${ }^{1}$ Pengalaman mentor penulis ini sebenarnya hanyalah salah satu contoh yang menunjukkan bahwa untuk jangka waktu yang lama ternyata ada semacam sentimen negatif terhadap humor dalam kekristenan. Hal ini tidak mengherankan, sebab tanpa disadari tradisi Kristen memang mewariskan semacam tendensi anti-humor dalam gereja. Pada abad-abad permulaan, humor dianggap sebagai sesuatu yang negatif oleh mayoritas bapa gereja. ${ }^{2}$ Dalam hal ini, salah satu

\footnotetext{
${ }^{1}$ Lihat rekaman pertama seminar "Humor dalam Alkitab" oleh Yakub Tri Handoko, yang bisa diakses secara daring di https://www.youtube.com/watch?v=7EkT5MN4obM\&t=68s

${ }^{2}$ Nampaknya ada dua alasan utama mengapa para bapa gereja melihat humor sebagai hal yang negatif. Alasan pertama bersifat teologis. Para tokoh ini melihat bahwa kemunculan humor dalam Alkitab (khususnya dalam Perjanjian Lama) biasanya terkait dengan kebencian dan kebodohan [(band. John Morreall, "Philosophy and Religion", in Victor Raskin (ed.), The Primer of Humor Research (Berlin: Mouton de Gruyter, 2008), 212-3]. Terkait kebencian, hal ini bisa dilihat dalam tawa Allah di dalam Mazmur 2, yang muncul dalam konteks ejekan. Tawa Elia terhadap nabi-nabi Baal (1 Raja-Raja 18:20-46) maupun tawa
} 
contoh yang paling mengemuka ialah Yohanes Krisostomus. Dalam salah satu khotbahnya, dia pernah menulis demikian:

Thus laughter often gives birth to foul discourse, and foul discourse to actions still more foul. Often from words and laughter proceed railing and insult; and from railing and insult, blows and wounds; and from blows and wounds, slaughter and murder. If, then, you would take good counsel for yourself, avoid not merely foul words, and foul deeds, or blows, and wounds, and murders, but unseasonable laughter, itself, and the very language of banter; since these things have proved the root of subsequent evils (The Homilies on the Statues to the People of Antioch, Homily XV. 11)

sekelompok anak kecil terhadap Elisa karena kebotakannya (2 Raja-Raja 2:2324) juga dianggap mengandung konotasi yang sama. Sementara mengenai kebodohan, tawa Abraham dan Sarah terhadap janji Allah merupakan teks yang representatif (Kejadian 17:17; 18:12-15). Morreall menjelaskan jalan berpikir para tokoh ini, "Abraham and Sarah's laughter did not express superiority or scorn towards God, but it did show two serious shortcomings: the intellectual inability to imagine the maker of heaven and earth performing a simple miracle, and a lack of trust in God." (Morreall, "Philosophy and Religion", 212; band juga James H. Charlesworth, How Barisat Bellowed: Folklore, Humor, and Iconography in the Jewish Apocalypses and the Apocalypse of John. DSSCOL 3 [North Richland Hill, TX: Bibal, 1998], 9-10). Beberapa nasihat yang disampaikan oleh Qoheleth juga terlihat mengaitkan tawa dengan kebodohan dan kesia-siaan (Pengkhotbah 2:2; 7:3-6). Selain itu, rujukan kepada teladan Kristus juga mengharuskan mereka menghindari tawa (lihat catatan kaki nomor 4; lih. Willie Van Herden, "Why the Humour in the Bible Plays Hide and Seek with Us", in Social Identities 7/1 [2001]: 84). Alasan kedua terkait dengan pengaruh filosofis. Beberapa filsuf ternyata mengaitkan tawa sebagai wujud sikap antisosial yang lahir dari kurangnya pengendalian diri. Ide ini khususnya terlihat jelas dalam pemikiran Plato. Van Herden menuliskan, "Plato claimed that humour is harmful because it involves the suspension of our highest faculty, our reason. Laughter is therefore to be suppressed, because it promotes and expresses silliness and irresponsibility, which are less than fully human qualities" (Van Herden, "Why the Humour in the Bible", 81). Akibatnya, tentu saja para bapa gereja awal (yang umumnya dipengaruhi Plato) juga cenderung melihat humor secara negatif.

${ }^{3}$ Teks ini bisa diakses secara daring di http://www.newadvent.org/fathers/190115.htm 
Di tempat lain, Krisostomus menyatakan bahwa tawa bukanlah sikap yang mengikuti teladan Kristus dan orang-orang Kudus. Sebaliknya, dia berpendapat bahwa justru dengan menangislah orang-orang Kristen sebenarnya sedang meneladani Kristus dan Paulus, dan bahkan mempersiapkan dirinya untuk mewarisi Kerajaan Allah. ${ }^{4}$ Setali tiga uang dengan Krisostomus, beberapa bapa gereja lainnya-semisal Klemens Aleksandria, Ambrosiaster, Hieronimus (Jerome), dan Basil Kaesarea-ternyata juga mengemukakan pendapat serupa dalam beberapa khotbah mereka. ${ }^{5}$

Pada era Monastik, keadaan ternyata tidak jauh berubah. Humor masih dipandang sebagai sesuatu yang negatif oleh banyak rahib. Morreall mendaftarkan beberapa contoh di antaranya:

The oldest monastic rule-of Pachom of Egypt in the fourth century-forbade joking. The Rule of St. Benedict, the foundation of Western monastic codes, enjoined monks to "prefer moderation in speech and speak no foolish chatter, nothing just to provoke laughter; do not love immoderate or boisterous laughter." In Benedict's Ladder of Humility, Step Ten was a restraint against laughter, and Step Eleven a warning against joking. The monastery of Columban in Ireland assigned these punishments: "He who smiles in the

\footnotetext{
${ }^{4}$ If you also weep thus, you have become a follower of your Lord. Yea, for He also wept, both over Lazarus, and over the city; and touching Judas He was greatly troubled. And this indeed one may often see Him do, but nowhere laugh, nay, nor smile but a little; no one at least of the evangelists has mentioned this. Therefore also with regard to Paul, that he wept, that he did so three years night and day, both he has said of himself, and others say this of him; but that he laughed, neither has he said himself anywhere, neither has so much as one other of the saints, either concerning him, or any other like him ...For this is not the theatre for laughter, neither did we come together for this intent, that we may give way to immoderate mirth, but that we may groan, and by this groaning inherit a kingdom (Homilies on Matthew VI.8-9). Teks khotbah ini bisa diakses secara daring di http://www.newadvent.org/fathers/200106.htm

${ }^{5}$ Lihat Stephen Halliwell, Greek Laughter: A Study of Cultural Psychology from Homer to Early Christianity (Cambridge: CUP, 2008), 512-9.
} 
service . . . six strokes; if he breaks out in the noise of laughter, a special fast unless it has happened pardonably." One of the strongest condemnations of laughter came from the Syrian abbot Ephraem: "Laughter is the beginning of the destruction of the soul, o monk; when you notice something of that, know that you have arrived at the depth of the evil. Then do not cease to pray God, that he might rescue you from this death. ",

Pada periode Puritanisme, cara pandang terhadap humor ternyata kian menjadi negatif. Beberapa tokoh Puritan bahkan menulis beberapa traktat untuk melawan humor dan komedi. William Pyrnne, misalnya, menganggap bahwa komedi adalah hal yang tidak sesuai dengan sikap hidup kristiani. Oleh karena itu, dia menasihatkan, orang Kristen tidak seharusnya melibatkan dirinya dalam sikap yang sembrono, sia-sia, dan berlebihan seperti demikian. $^{7}$

Dari skesta singkat ini, terlihat bahwa perjalanan sejarah kekristenan ternyata diwarnai oleh para pemikir yang anti-humor. Humor cenderung dianggap sebagai wujud keberdosaan, entah sebagai bentuk ekspresi kebencian atau absennya pengendalian diri. Willie Van Herden meringkaskan cara pandang ini dengan baik: "The greater the degree of holiness, the less the degree of laughter and humour." Cara pandang ini tak pelak melahirkan dua konsekuensi praktis dalam sejarah Kekristenan. Pertama, orangorang Kristen cenderung menghindari humor atau gurauan dalam kehidupan mereka sehari-hari, sebab hal tersebut dianggap sebagai tanda jauhnya hidup mereka dari kesalehan. Dengan kata lain, secara diam-diam, orang-orang Kristen cenderung dibentuk agar memiliki temperamen yang serius dan literal. Karena alasan ini,

\footnotetext{
${ }^{6}$ Morreall, "Philosophy and Religion”, 217.

${ }^{7}$ Lihat John Morreall, Comic Relief: A Comprehensive Philosophy of Humor (Malden, Ma: Wiley-Blackwell, 2009), 5-6.

${ }^{8}$ Van Herden, "Why the Humour in the Bible", 77.
} 
tidak heran jika dosen tadi harus memberikan teguran kepada mentor penulis. Bukankah tidak layak untuk menggunakan piranti keberdosaan dalam menyampaikan firman yang kudus di atas mimbar yang kudus? Kedua, orang-orang Kristen cenderung melewatkan (atau bahkan memungkiri) eksistensi humor dalam Alkitab. Karena humor adalah manifestasi keberdosaan, maka menganggap bahwa Alkitab mengandung dan menampilkan sikap yang demikian tentunya merupakan sikap yang tidak masuk akal, bila bukan penghujatan. ${ }^{9}$

Dalam tulisan ini, penulis tidak akan berfokus pada konsekuensi yang pertama. ${ }^{10}$ Sebaliknya, di sini penulis akan mencoba memberikan jawaban terhadap konsekuensi kedua. Karena keterbatasan ruang, tentu saja adalah hal yang mustahil untuk menunjukkan potensi humor dalam seluruh bagian Alkitab. Apa yang akan penulis lakukan dalam tulisan ini ialah

\footnotetext{
${ }^{9}$ Van Herden, "Why the Humour in the Bible", 81. Harus diakui bahwa tradisi Kristen bukanlah satu-satunya penyebab orang-orang Kristen dan pembaca modern lain tidak bisa menikmati humor dalam Alkitab. Penulis melihat (1) gap budaya dan bahasa antara masyarakat Alkitab (penulis dan penerimanya) dan pembaca modern, (2) perbedaan cara membaca antara masyarakat Alkitab dengan masyarakat modern, maupun (3) pengaruh para akademisi (bdk. catatan kaki 61), juga turut berperan menyebabkan banyak orang sulit mendeteksi keberadaan humor dalam Alkitab. Lih. Stefanus Kristianto, Jesus's Humor in the Antitheses (Unpublished MTh thesis; Singapore: Trinity Theological College, 2017), 26-31.

${ }^{10}$ Terkait hal ini Conrad Hyers memberi sebuah pendapat yang baik. Dia mengakui bahwa memang ada tawa yang terkait dengan kejatuhan (fallen laughter), yakni tawa yang ditujukan untuk mengolok seseorang atau meninggikan diri seseorang terhadap orang lain. Akan tetapi, dia menolak gagasan bahwa semua tawa adalah hal yang negatif. Sebaliknya, dia berpendapat bahwa humor dan tawa manusia berakar dalam Allah: manusia tertawa dan mengenali humor sebab manusia diciptakan menurut gambar Allah. Dengan kata lain, humor merupakan salah satu bagian dari karakter Allah. Oleh sebab itu, menolak humor karena menganggapnya sebagai sikap yang negatif merupakan sikap yang tidak berdasar. Humor, seperti yang Hyers jelaskan, merupakan salah satu anugerah Allah bagi manusia sebagai gambar-Nya. Lihat Conrad Hyers, And God Created Laughter: the Bible as Divine Comedy (Atlanta: John Knox, 1987), 9-23.
} 
menunjukkan bahwa sebuah teks Alkitab yang dibahas ternyata sangat mungkin mengandung potensi humor; ${ }^{11}$ dan bagian yang akan menjadi perhatian dalam tulisan ini ialah perumpamaan tentang pengampunan, yang terekam dalam Matius 18:21-35. Perumpamaan ini adalah salah satu perumpamaan Tuhan Yesus yang terkenal. Meski demikian, tidak banyak pembaca yang menyadari bahwa perikop ini mengandung beberapa potensi humor. $^{12}$

Untuk menunjukkan potensi humor dalam perikop ini, pertama-tama penulis akan mendiskusikan secara singkat mengenai definisi humor. Sesudahnya, penulis akan membahas konteks dan konten perumpamaan ini, sebelum akhirnya menunjukkan beberapa potensi humor dalam perikop ini. Apa yang menarik, bila interpretasi penulis dalam studi ini bisa diterima, itu berarti Alkitab (khususnya kitab Injil) bukan sekadar mengandung humor, tetapi lebih jauh lagi, Alkitab ternyata menampilkan Yesus sebagai sosok yang hidup dan humoris! (kontra Krisostomus). ${ }^{13}$

\footnotetext{
${ }^{11}$ Penting diingat bahwa studi humor dalam Alkitab bukanlah sebuah studi eksakta, melainkan sebuah studi interpretasi. Karena itu, ketika seorang penafsir berpendapat bahwa satu ayat atau bagian Alkitab mengandung humor, tentu saja derajat keyakinannya akan berbeda dengan saat ia mengatakan bahwa satu ditambah satu (dalam konteks perhitungan desimal!) adalah dua! Apa yang bisa seorang penafsir humor nyatakan ialah bahwa dengan berdasar pada sebuah teori atau konsep humor tertentu, sebuah ayat atau bagian Alkitab yang dibahas sangat mungkin (probably) mengandung unsur humor.

12 Jakob Jónsson sebenarnya tidak terlalu yakin apakah perikop ini memang mengandung humor. Meski demikian, ia melihat bahwa perubahan sikap yang tiba-tiba yang dilakukan si hamba nampaknya berpotensi mengandung unsur komikal (lihat Humor and Irony in the New Testament: Illuminated by Parallels in Talmud and Midrash [Leiden: Brill, 1965], 134-6). Sayangnya, Jónsson tidak mengelaborasi pendapatnya lebih jauh, sehingga usulannya menjadi tidak jelas. ${ }^{13}$ Selain Krisostomus, beberapa pemikir lain juga berpendapat bahwa Yesus adalah pribadi yang anti-humor, misalnya Nietzsche, Harris, dan Chesterton. Lihat Henry F. Harris, "The Absence of Humor in Jesus", in Methodist Quarterly Review 57/3 (July 1908): 460-7; Gilbert K. Chesterton, Heretics/Orthodoxy (Nashville: Thomas Nelson, 2000), 311.
} 


\section{MENDEFINISIKAN HUMOR}

Apakah humor itu? The Oxford Advanced American Dictionary memberikan tiga pilihan definisi, yaitu: (1) the quality in something that makes it funny or amusing; the ability to laugh at things that are amusing; (2) the state of your feelings or mind at a particular time; and (3) one of the four liquids that were thought in the past to be in a person's body and to influence health and character. ${ }^{14}$ Dari ketiga definisi di atas, terlihat jelas bahwa hanya ada satu definisi yang terkait dengan studi humor, yakni definisi pertama. Hanya saja, definisi tersebut tidak menjelaskan sifat dasar humor kepada pembacanya.

Diskusi mengenai sifat dasar atau natur humor memang tidak pernah menjadi diskusi yang mudah, sehingga tidak mengherankan bila lantas para sarjana Alkitab cenderung menghindari diskusi ini dan memilih memberi pengertian minimal mengenai humor. Rogness, misalnya, mendefinisikan humor sebagai: "those situations, comments, or stories that would cause us to smile, chuckle, or even laugh."15 Akan tetapi, dalam halaman awal artikelnya, dia menuliskan:

What is humorous or funny depends as much on the listener or viewer as the situation or humorist, so an exact definition is impossible. Defining humor is much like Supreme Court Justice Potter Stewart trying to define "obscenity" in a 1964 case before the court (Jacobellis V. Ohio). He wrote, "I shall not today attempt further to define the kinds of material I understand to be embraced ... but I know it when I see it. " An adequate definition of humor is impossible, but we "know it when we see it." 16

\footnotetext{
${ }^{14}$ Oxford Advanced American Dictionary (Oxford: OUP, 2011), 740.

${ }^{15}$ Michael Rogness, "Humor in the Bible", in Word \& World 32/2 (2012): 119.

${ }^{16}$ Rogness, "Humor in the Bible", 117. Penekanan oleh penulis.
} 
Kesimpulan yang sama juga bisa ditemukan dalam studi yang dilakukan John Reid dan Yehuda Radday. Reid berpendapat bahwa kualitas humor sebenarnya menolak semua upaya definisi. Bagi Reid, humor hanya bisa dirasakan dan dinikmati, tetapi tidak bisa didefinisikan dengan pasti. ${ }^{17}$ Senada dengan Reid, Radday juga meyakini bahwa konsep humor sebenarnya menolak semua upaya definisi yang dilakukan manusia. ${ }^{18}$ Bednarz merupakan contoh yang lain. Di dalam disertasinya, dia tidak sedikitpun membahas sifat humor. ${ }^{19}$ Hal ini menjadi jelas dalam sebuah publikasi yang diterbitkannya kemudian. Dia berpendapat bahwa sarjana Alkitab telah bersikap bijak dengan menghindari diskusi yang kompleks mengenai teori humor. Dia melanjutkan, observasi sederhana bahwa humor terdiri atas beberapa bentuk keganjilan (incongruity) sudah lebih dari cukup untuk menjadi landasan dalam studi humor Alkitab. ${ }^{20}$

Bila para sarjana tadi mewakili kelompok pesimisitis, beberapa sarjana lain ternyata cukup percaya diri dalam menguraikan natur humor. Jakob Jónsson, misalnya, mengalokasikan satu bab khusus untuk membahas natur humor dan ironi. $^{21}$ Dia mejelaskan bahwa studi humor pada dasarnya merupakan studi mengenai sesuatu yang lucu (comical). Dia lantas mengaitkan kelucuan ini dengan beberapa elemen lain, seperti sifat menggelikan (ludicrousness), kemenangan atas sesuatu yang tidak

\footnotetext{
${ }^{17}$ Dikutip dalam Jónsson, Humor and Irony, 16.

${ }^{18}$ Yehuda T. Radday, "On Missing the Humour in the Bible: An Introduction", dalam Yehuda T. Radday and Athalya Brenner (eds.), On Humour and Comic in the Hebrew Bible (Sheffield: Almond, 1990), 23.

${ }^{19}$ Terri Bednarz, Humor-neutics: Analyzing Humor and Humor Function in the Synoptic Gospels (Unpublished Ph.D dissertation, Texas Christian University, 2009).

${ }^{20}$ Terri Bednarz, Humor in the Gospels: A Sourcebook for the Study of Humor in the New Testament 1863-2014 (Lanham: Lexington, 2015), 10. Bdk. juga Erik Thoennes, "Laughing through Tears: Redemptive Role of Humor in in a Fallen World", in Presbyterion 33/2 (2007): 76.

${ }^{21}$ Jónsson, Humor and Irony, 16-34.
} 
disukai, keganjilan (incongruity), inkoherensi, dan sebagainya. ${ }^{22}$ Sementara itu, Leslie Flynn, sebagai perwakilan suara optimistis lainnya, juga mencoba mendefinisikan hal-hal yang mendorong seseorang tertawa. Dia mencatat bahwa humor sebenarnya mencakup salah satu dari beberapa elemen ini: keganjilan (incongruity), superioritas, kebaikan, dan kejutan (unexpectedness). ${ }^{23}$ Tidak seperti Jónsson dan Flynn yang memberi definisi yang luas, Palmer membatasi esensi humor hanya pada aspek kejutan. Dia menuliskan, "[t]here is a surprise at the center of everything that is funny." 24 Dari paparan singkat ini terlihat jelas bahwa nampaknya tidak ada definisi yang sama di antara para sarjana yang optimis ini.

Tidak bisa disangkal bahwa memang, dalam taraf tertentu, ada aspek subyektif dalam pengenalan seseorang terhadap humor: apa yang dianggap seseorang lucu, belum tentu dianggap lucu oleh orang lain. ${ }^{25}$ Karena alasan inilah, maka diperlukan sebuah definisi tentang humor meskipun sifatnya tentatif. Sebab bila tidak, maka studi humor akan menjadi sangat subyektif, yakni hanya mencerminkan selera humor dari pembaca atau penafsir. ${ }^{26} \mathrm{Di}$ sisi lain, tidak bisa juga disangkal bahwa mendefinisikan humor adalah sebuah tugas yang rumit, sehingga mencapai sebuah definisi yang

\footnotetext{
22 Jónsson, Humor and Irony, 17-8.

${ }^{23}$ Leslie B. Flynn, Serve Him with Mirth: The Place of Humor in Christian Life (Grand Rapids: Zondervan, 1960), 41-9.

${ }^{24}$ Earl F. Palmer, The Humor of Jesus: Sources of Laughter in the Bible (Vancouver: Regent College, 2001), 15.

${ }^{25}$ Bdk. Donald Capps, A Time to Laugh: the Religion of Humor (New York: Continuum, 2005), 2; Kelly Iverson, "Incongruity, Humor, and Mark:

Performance and the Use of Laughter in the Second Gospel”, in NTS 59 (2013): 5.

${ }^{26}$ Terkait studi humor terhadap literatur kuno, Meltzer memberikan peringatan serupa, "Anyone attempting to discuss the humor of an extremely different and distant culture will indubitably reveal much more about his/her sense of humor than about that of the people under study." Edmund S. Meltzer, "Humor and Wit, Ancient Egypt", in David Noel Freedman (ed.), The Anchor Bible Dictionary (New York: Doubleday, 1996), 3: 326.
} 
tepat mengenai humor pasti menjadi sangat sulit (bila bukan mustahil). Nyatanya, apa yang bisa dicapai sejauh ini ini ialah pemahaman yang cukup mengenai humor. Meski demikian, penulis tidak melihat definisi yang ditawarkan oleh para sarjana di atas sebagai definisi yang cukup tepat untuk mendefinisikan humor. Sebagian dari definisi tersebut sifatnya terlalu luas, sementara yang lainnya terlalu sempit. Karena itu, penulis akan menggunakan definisi dari studi mutakhir mengenai humor dalam bidang filsafat dan psikologi sebagai landasan definisi penulis.

Dalam studi psikologi dan filsafat, sebenarnya ada beragam teori yang telah dimunculkan mengenai natur atau sifat humor. Di antara berbagai macam teori tersebut, tiga teori yang paling terkemuka ialah teori superioritas, teori pelepasan dan kelegaan (the release and relief theory), serta teori keganjilan (the incongruity theory). ${ }^{27}$ Masing-masing teori ini tentu memiliki kelebihan dan kekurangan. ${ }^{28}$ Meski demikian, banyak pemikir mengakui bahwa teori keganjilan merupakan teori yang paling unggul dibandingkan berbagai teori lain. Carroll menulis alasannya, "it offers the most informative approach to locating the structure of the intentional object of comic amusement."29 Akibatnya, tidak heran bahwa teori ini kini menjadi teori dominan dalam studi humor. ${ }^{30}$ Martin, misalnya, mengakui bahwa mayoritas peneliti humor kini kian menyadari bahwa humor mencakup

\footnotetext{
${ }^{27}$ Di samping ketiga teori ini, masih ada beberapa teori lain mengenai humor, semisal teori permainan, teori disposisi, teori kejutan, teori ambivalensi, teori konfigurasi, dan sebagainya. Lihat Patricia Keith Spiegel, "Early Conception of Humor: Varieties and Issues", in Jeffery H. Goldstein and Paul E. McGhee, The Psychology of Humor: Theoretical Perspectives and Empirical Issues (New York: Academic, 1972), 4-13; Noel Carroll, Humour: A Very Short Introduction (Oxford: OUP, 2014), 7-54.

${ }^{28}$ Untuk analisa singkat terhadap tiga teori tersebut, lihat Kristianto, Jesus's Humor in the Antitheses, 10-17.

${ }^{29}$ Carroll, Humour, 48.

${ }^{30}$ Carroll berkomentar, "the Incongruity theory of humour has attracted the largest allegiance among philosophers and psychologists" (Carroll, Humour, 17).
} 
keganjilan. ${ }^{31}$ Ruch menambahkan bahwa hari ini nampaknya ada persetujuan yang luas bahwa keganjilan merupakan kondisi yang niscaya untuk terjadinya humor. ${ }^{32}$

Secara sederhana, teori keganjilan berpendapat bahwa manusia belajar dari pengalaman mereka dan menciptakan sebuah pola dari pemahaman mereka atas pengalaman tersebut. Manusia tahu bahwa api itu panas, salju itu dingin, dan bahwa manusia tidak memiliki kemampuan untuk terbang karena mereka membuat pola dari pengalaman mereka. Jadi, menurut teori ini, humor terjadi ketika pola tersebut dilanggar atau ketika ekspektasi, yang didasarkan pada pola yang dipelajari tersebut, ternyata tidak terjadi. $^{33}$ Bila teori ini diterima, maka beberapa sarjana yang mengaitkan humor dengan keganjilan (mis. Bednarz, Jónsson, Flynn, Thoennes) berarti sudah berada di jalur yang benar.

Meski demikian, teori ini bukannya tanpa kritik. Setidaknya ada dua keberatan utama terhadap teori keganjilan ini. Pertama, beberapa pemikir menyadari bahwa keganjilan per se tidaklah cukup untuk menjelaskan sifat dari humor. Ruch, misalnya, berpendapat bahwa keganjilan semata tidak otomatis menghasilkan humor, sebab hal tersebut juga bisa mendorong timbulnya kebingungan atau bahkan reaksi yang negatif. ${ }^{34}$ Morreall menjelaskan lebih jauh:

\footnotetext{
${ }^{31}$ Rod A. Martin, The Psychology of Humor: An Integrative Approach (Burlington: Elsevier, 2007), 6

${ }^{32}$ Lih. Willibald Ruch, "Psychology of Humor", in Raskin (ed.), The Primer of Humor Research, 25.

${ }^{33}$ Bdk. Morreal, Comic Relief, 11; Carroll, Humour, 17-18. Carroll mengingatkan bahwa kata 'ekspektasi' dalam teori keganjilan bukan merujuk pada ekspektasi spesifik, melainkan ekspektasi yang bersifat global, yakni tentang "how the world is or should be" (Carroll, Humour, 18).

${ }^{34}$ Ruch, "Psychology of Humor", 25.
} 
In the late twentieth century, one serious flaw in several older versions of the theory came to light: they said or implied that the mere perception of incongruity is sufficient for humor. That is clearly false, since negative emotions like fear, disgust, and anger are also reactions to what violates our mental patterns and expectations. Coming home to find your family murdered, for example, is incongruous but not funny. Experiencing something incongruous can also evoke puzzlement or incredulity: we may go into a problem-solving mode to figure out how the stimulus might actually fit into our conceptual frameworks. ${ }^{35}$

Kritik ini tentu perlu diperhatikan dengan serius, sebab tidak ada seorang pun yang akan menganggap keganjilan yang berbahaya untuk dirinya sebagai sesuatu yang menyenangkan. Ini berarti teori tersebut memerlukan penjelasan tambahan untuk menjadikannya lebih sempurna. Beberapa pendukung teori ini kemudian menambahkan satu aspek lagi untuk memperkuat teori ini, yakni aspek "keamanan" (safeness) atau "non-serius." 36 Ketika sebuah keganjilan bersifat aman atau non-serius, maka seseorang tentunya lebih bisa menikmati keganjilan tersebut. Dengan kata lain, keganjilan itu akan terlihat menyenangkan dan bukan mengerikan. Martin meringkaskan versi revisi ini dengan baik: “... the essence of humor seems to be incongruity, unexpectedness, ${ }^{37}$ and playfulness, which evolutionary theorists Matthew Gervais and David Wilson (2005) referred to as 'nonserious social incongruity., ,38

Keberatan lain terhadap teori ini ialah "the irrational objection." Seperti yang dijelaskan di atas, teori ini mengaitkan kemunculan humor dengan terjadinya pelanggaran terhadap pola

\footnotetext{
${ }^{35}$ Morreall, Comic Relief, 12-3.

${ }^{36}$ Ruch, "Psychology of Humor", 25; Carroll, Humour, 29-30.

${ }^{37}$ Carroll menolak ide bahwa bahwa 'kejutan' merupakan unsur yang niscaya untuk terjadinya humor (Humour, 17-8).

${ }^{38}$ Martin, The Psychology of Humor, 6.
} 
konseptual yang dibuat manusia. Pertanyaannya ialah: bagaimana bisa seseorang menikmati pelanggaran terhadap pola konseptualnya? Morreall menjelaskan, "Such enjoyment looks psychologically perverse or at least irrational. That is why, although the Incongruity Theory freed humor from the traditional stigma of being anti-social, it has not improved philosophers' assessments of humor much over the last three centuries." ${ }^{39}$ Dia menambahkan lebih jauh bahwa kecenderungan manusia ialah mengatasi keganjilan dan membuatnya bisa dijelaskan secara teoritis, bukan menikmatinya. Karena itu, dia dan beberapa pemikir lain memandang bahwa teori keganjilan sebenarnya tidak secara lengkap menjelaskan natur atau sifat dasar dari humor.

Meresponi kritik ini, ada dua hal yang perlu dicatat. Pertama, kritik Morreall hanya bisa dibenarkan ketika seseorang mengabaikan aspek 'kelucuan' (playful) dari sebuah keganjilan. Dengan kata lain, jika seseorang merasa bahwa pola konseptualnya sedang dilanggar itu berarti orang tersebut mencerna humor terlalu serius, dan dengan demikian kehilangan aspek jenaka dari sebuah humor. Kedua, ketika seseorang menangkap aspek jenaka dari sebuah humor, hal itu akan membawanya pada kenikmatan (enjoyment) atas humor tersebut. Carroll menjelaskan bahwa kejenakaan sebuah keganjilan akan membawa seseorang terlepas dari "tirani norma dan konsep sehari-sehari." Dia melanjutkan, "it does not give way to higher sense (i.e. explanation or overcome the incongruity); it leads to nonsense." ${ }^{40}$ Dua hal ini, membuat keberatan Morreall menjadi tidak beralasan.

Selain dua keberatan tadi, tentunya ada satu dua keberatan lain terhadap teori keganjilan. Tetapi, karena teori ini merupakan teori yang paling bermanfaat dan memberi harapan (di samping

\footnotetext{
${ }^{39}$ Morreall, Comic Relief, 13.

${ }^{40}$ Carroll, Humour, 69.
} 
juga teori yang dominan), maka penulis akan menggunakan teori ini sebagai landasan dalam tulisan ini. Singkatnya, dalam mendefinisikan natur humor, penulis bergantung pada teori keganjilan yang telah direvisi, yang memahami humor terkait erat dengan ide, gambar, teks, atau peristiwa yang ganjil dan aman atau non-serius, sehingga hal tersebut menjadi menyenangkan dan bisa dinikmati.

\section{KONTEKS DAN KONTEN PERUMPAMAAN}

Dibanding ketiga Injil yang lain, Injil Matius bisa dibilang merupakan Injil yang paling ekklesiastikal atau mengandung perhatian gerejani paling kuat. Selain karena Matius adalah satu-

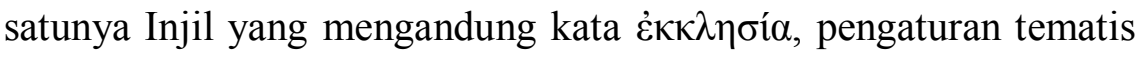
Injil ini nampaknya mencerminkan salah satu tujuan Injil ini, yakni sebagai buku katekisasi bagi gereja perdana. ${ }^{41}$ Perhatian ekklesial Matius ini juga terlihat cukup kuat dalam keseluruhan Matius 18. Raymond Brown bahkan melihat keseluruhan pasal ini sebagai sebuah khotbah terhadap gereja. ${ }^{42}$

Menarik dicatat, Matius meletakkan perumpamaan tentang pengampunan ini tepat setelah perikop mengenai disiplin gerejani (Matius 18:15-20). Melalui penempatan ini, Matius nampaknya ingin menegaskan bahwa disiplin gerejani harus berjalan berbarengan dengan pengampunan. Allison berpendapat, "Its function is to be a hedge against rigidity and absolutism, to balance the hard teaching of the previous paragraph. The concern is to avoid any calculus of 'less and more' and to make explicit the attitude that is necessary if one is to undertake the hard task of

\footnotetext{
${ }^{41}$ E.g. Joachim Jeremias, The Sermon on the Mount (Philadelphia: Fortress, 1963), 19-23.

${ }^{42}$ See Raymond E. Brown, An Introduction to the New Testament (New York: Doubleday, 1997), 191.
} 
correcting a brother." ${ }^{\text {43 }}$ Sedikit berbeda dengan Allison, penulis melihat bahwa kedua perikop ini bersifat saling menyeimbangkan satu sama lain. Dengan kata lain, Matius nampaknya hendak mengajar bahwa disiplin tanpa pengampunan sama tidak bergunanya dengan pengampunan tanpa disiplin.

Perikop ini dimulai dengan pertanyaan Petrus kepada Yesus tentang berapa kali ia harus mengampuni saudaranya yang bersalah kepadanya (ay. 21). Menilik penggunaan kata $\alpha \delta \varepsilon \lambda \varphi \circ \varsigma$ dalam bagian lain Injil Matius (misal: 12:50; 23:8; 25:40), sangat mungkin bahwa saudara yang dimaksud berbicara lebih dari sekadar saudara secara biologis, yakni saudara secara rohani atau sesama saudara seiman. Apa yang mungkin menarik dalam prolog ini ialah angka yang diajukan Petrus kepada Yesus: "Sampai tujuh

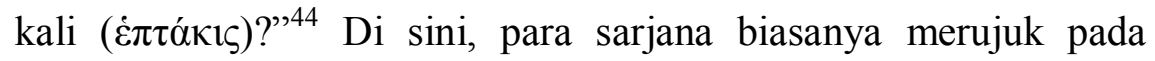
sebuah teks rabbinik yang mungkin melatarbelakangi proposal Petrus. Dalam sebuah Talmud Babilonia (b. Yoma 86b), dinyatakan bahwa tiga adalah jumlah maksimal seseorang bisa mengampuni:

It was taught in a baraita that Rabbi Yosei bar Yehuda says: When a person commits a transgression the first time, he is forgiven; a second time, he is forgiven; a third time, he is forgiven; but for the fourth time, he is not forgiven, as it is

\footnotetext{
${ }^{43}$ W. D. Davies and Dale C. Allison, A Critical and Exegetical Commentary on the Gospel According to Saint Matthew (ICC; 3 Vols; London/New York: T\&T Clark, 2004), 2:791.

${ }^{44}$ Luz berpendapat bahwa di sini Petrus tidak sedang berbicara mengenai angka tujuh secara literal, melainkan angka tujuh sebagai simbol kesempurnaan. Ia menuliskan, "That Peter suggests forgiving seven times does not mean, therefore, that he wants to grant his brother only a limited forgiveness. Instead, the sense of Peter's question is: "Is perfect forgiveness expected of me?"'". Lihat Ulrich Luz, "Matthew", in Helmut Koester (ed.), Hermeneia (Minneapolis: Augsburg, 2001), 465. Interpretasi ini menarik, namun bila Luz benar, maka jawaban Yesus dalam bagian selanjutnya justru akan menjadi mubazir. Selain itu, konsep yang mungkin melatarbelakangi usulan Petrus juga berbicara mengenai angka yang literal. Karena itu, penulis melihat nampaknya jauh lebih tepat memahami angka tujuh di sini secara literal.
} 
stated: "Thus said the Lord: For three transgressions of Israel, but for four I will not reverse it" (Amos 2:6). And it says: "All these things does God do twice or three times with a man" (Job 33:29). ${ }^{45}$

Masalahnya, tarikh Talmud ini terbilang cukup belakangan, sehingga agak sulit dipastikan apakah tradisi ini memang bisa ditarik hingga ke abad pertama. Akan tetapi, seandainya tradisi ini memang cukup awal, ini berarti Petrus telah menyodorkan sebuah angka yang cukup fantastis! Ia telah mengusulkan sebuah angka yang jauh melebihi batas yang umum.

Meskipun Petrus menyodorkan angka yang cukup fantastis, tenyata Yesus tidak terkesan dengan itu. Sebaliknya, dia justru menolak usulan Petrus ${ }^{46}$ dan menyodorkan sebuah angka yang jauh

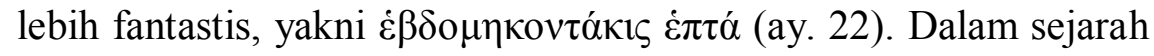
gereja, nominal angka yang disebut Yesus di sini ternyata telah diartikan dalam dua cara. Pertama, beberapa terjemahan awal Injil Matius menerjemahkan ungkapan tersebut sebagai "tujuh puluh kali tujuh kali" (yaitu empat ratus sembilan puluh). Terjemahan ini juga dipilih oleh beberapa versi Alkitab seperti TB-LAI, ASV, ESV, KJV, NASB, dan NLT. John Nolland nampaknya juga setuju dengan terjemahan ini. $^{47}$ Kedua, ungkapan ini juga bisa diterjemahkan "tujuh puluh tujuh kali." Terjemahan ini diadopsi oleh NAB, NIV, NJB, NRSV, dan didukung oleh beberapa sarjana seperti Carson, France, dan Turner. ${ }^{48}$ Dalam hemat penulis, frase

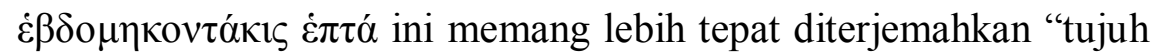

\footnotetext{
${ }^{45}$ Teks bisa diakses secara daring dari https://www.sefaria.org/Yoma.86b?lang=bi

${ }^{46}$ Penempatan partikel negasi oủ sebelum kata kerja $\lambda \varepsilon ́ \gamma \omega$ nampaknya bertujuan memberi penekanan.

${ }^{47}$ John Nolland, The Gospel of Matthew: A Commentary on the Greek Text (NIGTC; Grand Rapids/Carlisle: Eerdmans/Paternoster, 2005), 754-5.

${ }^{48}$ D. A. Carson, "Matthew", in Frank E. Gaebelein (ed.), EBC 8 (Grand Rapids: Zondervan, 1984), 405; R. T. France, The Gospel of Matthew. (NICNT; Grand Rapids: Eerdmans, 2007), 701; David L. Turner, Matthew (BECNT; Grand Rapids: Baker, 2008), 449.
} 
puluh tujuh," sebab frase ini muncul dalam LXX untuk menerjemahkan frase שבעים ושבעה (tujuh puluh tujuh) dalam Kejadian 4:24. Meski demikian, beruntung bahwa apapun terjemahan yang dipilih, hal ini tidak mengubah fakta yang sangat jelas, yakni bahwa ungkapan ini tidak untuk dipahami secara literal. Apa yang hendak Yesus tegaskan melalui ungkapan ini ialah bahwa murid-Nya harus mengampuni tanpa batas. Ketika murid Yesus menyadari bahwa Yesus menekankan kualitas pengampunan, maka pertanyaan mengenai kuantitas tidak lagi menjadi relevan.

Untuk memperjelas argumen-Nya, Yesus kemudian memberikan sebuah perumpamaan yang terkenal. Dikisahkan bahwa ada seorang raja yang mengadakan perhitungan dengan hamba-hambanya. Di tengah perhitungan tersebut, dia mendapati seorang hamba yang berhutang sangat besar kepadanya, yakni sebesar sepuluh ribu talenta. (ay. 23-24). ${ }^{49}$ Karena tidak mampu membayar hutangnya, maka sang raja (kini disebut, "sang tuan") memerintahkan agar orang tersebut beserta keluarga dan semua yang dimilikinya dijual untuk membayar hutang tersebut (ay. 25). Meski menjual orang tersebut merupakan tindakan yang legal, harus diakui tindakan demikian tetap tidak akan bisa melunaskan semua hutangnya. Tetapi raja ini nampaknya berpikir bahwa sedikit lebih baik ketimbang tidak sama sekali! ${ }^{50}$ Menyadari bahwa dirinya ada dalam keadaan di ujung tanduk, hamba tersebut lantas bersujud ( $\pi \varepsilon \sigma \omega ̀ v)$ dan menyembah ( $\pi \rho \circ \sigma \kappa v ́ v \varepsilon \imath)$ raja itu, serta memohon agar dirinya diberi tambahan waktu untuk melunaskan segala hutangnya (ay. 26). Penggunaan kata kerja Imperfek dalam bagian ini menyiratkan bahwa orang tersebut terus merengek meminta

\footnotetext{
${ }^{49}$ Penulis tidak akan membahas perdebatan apakah setting perumpamaan ini adalah Yahudi atau non-Yahudi, sebab diskusi tersebut tidak memberi dampak yang signifikan terhadap pemahaman teks.

${ }^{50}$ Bdk. Craig L. Blomberg, Matthew (NAC; Nashville: Broadman \& Holman Publishers, 2001), 283.
} 
tambahan waktu kepada sang raja. Apa yang menarik ialah respons dari sang raja. Ia tidak mengabulkan permintaan orang tersebut, melainkan memberi lebih dari apa yang dimintanya. Raja itu tidak memberi tambahan waktu, tetapi malah menghapuskan semua hutangnya! (ay. 27).

Kisah ini ternyata belum berakhir! Sesudah menerima pembatalan hutang, hamba ini pergi keluar dan "bertemu" dengan seorang hamba lain yang berhutang seratus dinar kepadanya (ay. 28). Terjemahan TB-LAI "bertemu" untuk kata cũ $\rho \varepsilon v$ dalam ayat ini mengesankan bahwa pertemuan ini terjadi secara tidak disengaja. Tetapi karena penggunaan kata ini di ay. 13 mengesankan pertemuan yang disengaja (lihat: mencari), maka nampaknya konotasi yang sama juga berlaku di sini. ${ }^{51}$ Dengan kata lain, hamba ini memang sengaja mencari rekannya untuk menagih hutangnya.

Bertolak belakang dengan kemurahan yang baru dia terima, hamba ini ternyata tidak menunjukkan belas kasihan sedikit pun kepada temannya ini. Sebaliknya, hamba ini malah menangkap dan mencekik temannya itu, serta memaksa dia membayar hutangnya yang sebesar seratus dinar itu. Apa yang dilakukan oleh teman dari hamba ini di ayat 29 jelas mengingatkan pembaca kepada tindakan yang dilakukan oleh si hamba di ayat 26: (1) sama seperti yang dilakukan si hamba di depan sang raja, teman hamba ini juga bersujud ( $\pi \varepsilon \sigma \omega ̀ v)$ dan memohon (bukan menyembah; $\pi \alpha \rho \varepsilon \kappa \alpha ́ \lambda \varepsilon \imath$ ) kepada hamba itu; (2) sama seperti si hamba meminta tambahan waktu untuk membayar hutangnya, teman hamba ini juga

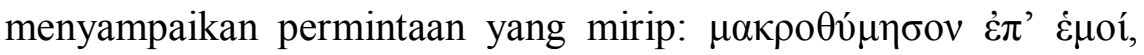

${ }^{51}$ Bdk. Nolland, The Gospel of Matthew, 758: "Does the released slave seek out his fellow slave or simply come upon him? \&ṽ $\rho \varepsilon v$ ('found') could connote either, but since the verb is used in v. 13 for a deliberate seeking out, that is more likely here." Band. juga Leon Morris, The Gospel According to Matthew (PNTC; Grand Rapids/Leicester: Eerdmans/Apollos, 1992), 475. 


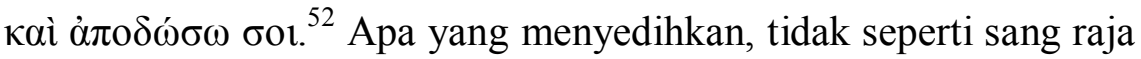
yang berbelas kasihan, hamba ini ternyata sama sekali tidak mau bermurah hati terhadap temannya, atau setidaknya memberi tambahan waktu. Dia justru menolak permintaan temannya dan melemparkan ( $\varepsilon \beta \alpha \lambda \varepsilon v)$ temannya itu ke penjara (ay. 30).

Apa yang dilakukan hamba ini sebenarnya termasuk berlebihan. Hutang temannya itu sebenarnya termasuk sangat kecil bila dibandingkan dengan hutangnya terhadap sang raja (bdk. catatan kaki 52). Selain itu, hutang temannya itu sebenarnya bisa terbayarkan! Ada beberapa cara untuk membayar hutang tersebut: (1) teman hamba itu bisa bekerja keras selama beberapa bulan dan membayar hamba tersebut atau (2) teman tersebut bisa bekerja kepada si hamba selama seratus hari! ${ }^{53}$ Yang manapun, poinnya sangat jelas: tidak seperti permintaan si hamba yang tidak masuk akal, permintaan teman hamba ini-agar dia diberi tambahan waktu-adalah permintaan yang sangat realistis. Akan tetapi, fakta bahwa si hamba tadi menangkap, mencekik, dan melemparkan temannya ke dalam penjara, menunjukkan bahwa sebenarnya tindakan hamba ini benar-benar keterlaluan!

\footnotetext{
52 Permintaan teman hamba ini tidak mengandung kata $\pi \alpha ́ v \tau \alpha$. Absennya kata ini nampaknya berfungsi untuk menunjukkan bahwa hutang orang ini sebenarnya terbilang kecil jika dibanding dengan hutang si hamba tadi.

${ }^{53}$ Matius 20:1-6 mencatat bahwa satu dinar adalah besaran upah harian untuk seorang pekerja. Bila demikian, teman hamba ini sebenarnya bisa bekerja selama seratus hari pada si hamba untuk membayar hutangnya. Sebuah pilihan lain untuk membayar hutang pada masa itu ialah dengan menjual seseorang sebagai budak untuk membayar hutangnya. Akan tetapi, dalam kasus ini, pilihan ini tidak bisa diambil sebab hukum Yahudi nampaknya melarang menjual seseorang bila nilai hutangnya jauh di bawah harga rata-rata budak. Seseorang hanya bisa dijual menjadi budak jika jumlah hutangnya lebih besar atau sama dengan harga pasar budak masa itu (lihat Mek. Ex. 22:2 [95b]; b. Qiddushin 18a). Carson mencatat bahwa harga termahal budak masa itu ialah satu talenta (enam ribu dinar), meski demikian harga budak yang umum pada masa itu ialah sepersepuluhnya atau kurang (sekitar lima hingga enam ratus dinar). Karena teman hamba ini hanya berhutang seratus dinar, itu berarti hutangnya jauh lebih kecil dari harga budak pada umumnya; dan karena itu, ia tidak boleh dijual menjadi budak. Bdk.

Carson, Matthew, 406-7; Luz, Matthew, 473.
} 
Kisah ini mendekati akhir ketika hamba-hamba yang lain-

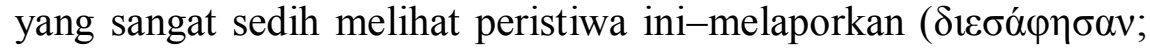
lihat: menceritakan dengan detil) kejadian ini kepada tuan mereka (sang raja; ay. 31). Tuan tersebut kemudian memanggil sang hamba tadi dan menegurnya dengan keras: "Hai hamba yang jahat, seluruh hutangmu telah kuhapuskan karena engkau memohonkannya kepadaku. Bukankah engkaupun harus mengasihani kawanmu seperti aku telah mengasihani engkau?" (ay. 32-33). Sebutan

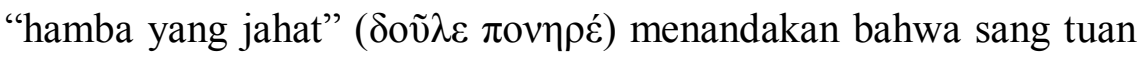
memandang perbuatan hamba tersebut sebagai hal yang kelewat batas. Ayat 33 menjelaskan alasan mengapa tuan tersebut merasa sangat tidak nyaman dengan perbuatan hamba tadi: hamba tadi tidak menunjukkan belas kasihan ( $\dot{\varepsilon} \lambda \varepsilon \tilde{\eta} \sigma \alpha \imath)$ kepada temannya sebagaimana sang tuan telah berbelas kasihan kepadanya $(\dot{\eta} \lambda \dot{\varepsilon} \sigma \alpha)$. Akibatnya, tuan yang marah tadi menyerahkan hamba tersebut kepada para algojo (lihat: penyiksa) untuk disiksa sampai ia dapat membayar semua hutangnya (ay. 34). Ada sebuah ironi yang

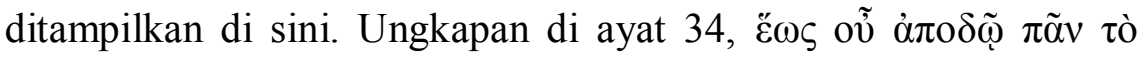
ỏ $\varphi \varepsilon \imath$ ó $\mu \varepsilon v o v$, mengingatkan pembaca pada ekspresi yang muncul

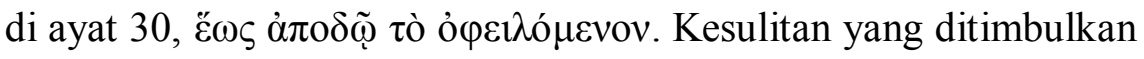
si hamba tadi kepada temannya kini terjadi kepada dirinya sendiri, bahkan dengan tingkat penderitaan yang lebih tinggi: hamba itu melemparkan temannya ke penjara hingga temannya itu bisa membayar hutangnya, kini hamba itu diserahkan kepada para algojo (penyiksa) hingga hamba itu bisa membayar semua hutangnya.

Sederhananya, perumpamaan ini memberi dua landasan mengapa murid Kristus harus mengasihi dengan kualitas tanpa batas. Pertama, Allah telah memberikan pengampunan yang besar kepada mereka. Oleh sebab itu, mereka pun dituntut untuk mengampuni saudara seiman yang bersalah kepada mereka. Hal ini penting sebab kesalahan yang diperbuat saudara seiman terhadap mereka selalu jauh lebih kecil jika dibanding kesalahan yang telah 
mereka lakukan terhadap Allah. Bila Allah berkenan memberi pengampunan yang besar, maka demikian pula seharusnya sikap murid Kristus terhadap saudara seimannya. Kedua, Allah akan menghukum murid Kristus yang tidak mau mengampuni saudara seimannya. Ide ini nampak jelas dalam kalimat penutup perumpamaan ini: "Maka Bapa-Ku yang di sorga akan berbuat demikian juga terhadap kamu, apabila kamu masing-masing tidak mengampuni saudaramu dengan segenap hatimu" (ay. 35).

\section{BEBERAPA POTENSI HUMOR}

Penulis melihat ada beberapa potensi humor dalam perikop ini. Potensi pertama muncul dalam jumlah hutang si hamba terhadap sang raja. Di ayat 24, dikatakan bahwa hamba tadi berhutang sebesar sepuluh ribu talenta terhadap sang raja. Jumlah ini benar-benar jumlah yang fantastis dalam konteks masa itu dan jelas merupakan sebuah hiperbola atau exaggeration, sebab orang ini berhutang dalam nominal terbesar pada masa itu: dia berhutang dalam angka terbesar (sepuluh ribu, $\mu \nu \rho i ́ \omega v$, adalah bilangan terbesar dalam numerologi kuno) dan dalam satuan yang terbesar

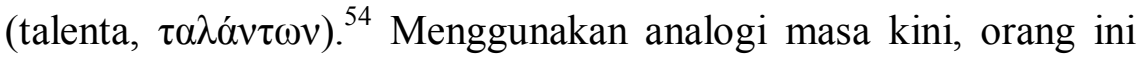
seibarat berhutang "sembilan puluh sembilan trilyun trilyun rupiah": sebuah nominal dengan dua puluh empat angka nol di belakang. $^{55}$ Hiperbola jumlah hutang ini sangat mungkin mengandung unsur humor meski relatif ringan.

${ }^{54}$ Bdk. Davies and Allison, the Gospel According to Saint Matthew, 1: 798; Blomberg, Matthew, 283; Luz, Matthew, 471 n. 30.

${ }^{55}$ Carson mengatakan bahwa jumlah hutang ini mungkin setara dengan lebih dari satu milyar dolar dalam mata uang masa kini (Carson, Matthew, 406). Sementara Blomberg mengestimasi hutang ini setara dengan lebih dari satu trilyun dolar (Blomberg, Matthew, 283). Yang manapun, Mitch dan Sri dengan tepat menjelaskan bahwa bagi pendengar abad pertama jumlah hutang ini terdengar seperti sebuah hutang yang tak terhitung nilainya. Lihat Curtis Mitch and Edward Sri, The Gospel of Matthew (Catholic Commentary on Sacred Scripture; Grand Rapids: Baker, 2010), 234. 
Keener juga sependapat bahwa nominal "sepuluh ribu talenta" di sini memang mengandung unsur humor, meski dia memiliki penjelasan yang berbeda. Ia menulis:

Further, the real worth of the debt in this story may be greater still: 10,000 being the largest single number Greek could express and the talent being the largest unit of currency, Jesus is making the parable particularly graphic. The combined annual tribute of Galilee and Perea just after the death of the repressive Herod the Great came to only 200 talents (Jos. Ant. 17.318; Jeremias 1972: 30); the tribute of Judea, Samaria, and Idumea came to 600 talents (Jos. Ant. 17.320). This fact starkly reveals the laughably hyperbolic character of the illustration: the poor man owes the king more money than existed in circulation in the whole country at the time! Jesus' hearers would scoff that the man was a fool to get so far in debt, and that the king had been a fool to let him get away with it. ${ }^{56}$

Analisa Keener ini menarik, meskipun penulis sebenarnya memiliki keraguan yang besar apakah Yesus memang mengajak pendengarnya berpikir sedemikian jauh tentang jumlah uang yang beredar saat itu. Tetapi bila interpretasi Keener benar, ini akan menguatkan tesis penulis bahwa ada "keganjilan yang menyenangkan" dalam jumlah hutang ini. Tetapi meskipun tidak, tesis penulis tetap cukup kuat sebab hiperbola memang merupakan salah bentuk perangkat humor yang cukup populer (misalnya Matius 7:4-5; 19:24).

Beberapa sarjana memang mencoba merasionalisasi jumlah hutang ini dengan menafsirkan bahwa hamba ini mungkin adalah

\footnotetext{
${ }^{56}$ Craig S. Keener, The Gospel of Matthew: A Socio-Rhetorical Commentary (Grand Rapids: Eerdmans, 2009), 458-9. Penekanan oleh penulis.
} 
pegawai kerajaan atau penarik pajak atau gubernur wilayah. ${ }^{57}$ Sementara, beberapa sarjana yang lain berpendapat bahwa awalnya Yesus mungkin mencetuskan sebuah jumlah yang lebih kecil, yang kemudian diperbesar oleh Matius. ${ }^{58}$ Akan tetapi, penjelasan ini gagal menangkap natur dari sebuah perumpamaan. Hagner dengan tepat menjelaskan bahwa perumpamaan memang sering menggunakan bahasa maupun ungkapan hiperbolis untuk memberi efek pada pendengar maupun pembacanya. Karena itu, dia menegaskan bahwa tidak ada alasan bahwa setiap poin dalam perumpamaan harus dicari korelasinya terhadap realitas yang historis. ${ }^{59}$ Dengan kata lain, penulis melihat lebih tepat untuk membiarkan nominal ini di sana dan menikmati efek yang ditimbulkannya, ${ }^{60}$ ketimbang berupaya menjelaskannya. ${ }^{61}$

Potensi humor yang kedua muncul terkait dengan permintaan si hamba kepada sang raja. Ketika sang raja akan menjual si hamba dan keluarganya, beserta dengan segala yang dimilikinya, hamba itu bersujud dan menyembah raja, serta memohon kepada sang raja agar dia diberi tambahan waktu untuk melunaskan segala

\footnotetext{
${ }^{57}$ Misalnya Grant Osborne, Matthew (ZECNT; Grand Rapids: Zondervan, 2010), 694; Morris, The Gospel According to Matthew, 472; Robert H. Mounce, Matthew (NIBC: Peabody: Hendrickson, 1991), 177; Luz, Matthew, 471.

${ }_{58}$ Misalnya Davies and Allison, The Gospel According to St. Matthew, 1:797; Nolland, The Gospel of Matthew, 756.

${ }^{59}$ Donald A. Hagner, Matthew 14-28 (WBC 33b; Dallas: Word, 2002), 538.

${ }^{60}$ Tentu saja efek teologis utama yang hendak disampaikan ialah mengenai betapa besarnya dosa dan kesalahan seseorang terhadap Allah.

${ }^{61}$ Radday menyadari bahwa tradisi akademik cenderung melahirkan para penafsir yang serius. Ia menulis bahwa mayoritas sarjana Alkitab hari ini dipengaruhi oleh para profesor Jerman abad ke sembilan belas, yang cenderung membaca teks dengan cara yang terlalu serius. Dengan bahasa humoris, ia melanjutkan bahwa itu sebabnya para profesor ini dianugerahi gelar honoris causa, dan bukannya humoris causa (Lihat Radday, "On Missing the Humour in the Bible", 33). Akibatnya, ketika mereka membaca Alkitab, mereka terpola mencurahkan mayoritas waktu dan perhatiannya pada aspek gramatik dan linguistik dengan tujuan menemukan makna dari teks Alkitab, tetapi mengabaikan 'kehidupan teks' (the life of the text; istilah ini dipinjam dari Jónsson, Humor and Irony in the New Testament, 312).
} 
hutangnya (ayat 26). Sang raja, yang tergerak oleh belas kasihan, akhirnya memutuskan untuk membebaskan si hamba dan menghapuskan segala hutangnya (ayat 27). Pembaca modern yang membaca bagian ini umumnya langsung mengaitkan bagian ini dengan gambaran Allah yang penuh kasih. Pembacaan demikian tentu tidak salah. Akan tetapi, pembacaan itu melewatkan hiburan kecil yang ditampilkan perumpamaan ini. Permintaan si hamba di ayat 26 sebenarnya sangat mungkin mengandung unsur humor. Permintaan ini sebenarnya terdengar konyol mengingat bahwa jumlah hutangnya yang tidak terhingga. Dengan kata lain, permintaan si hamba ini pada dasarnya benar-benar tidak realistis. Sejalan dengan penulis, Ulrich Luz ternyata juga mendeteksi adanya potensi humor di sini. Ia mengatakan bahwa keyakinan orang tersebut-bahwa dia pasti mampu membayar semua hutangnya-tentu akan menimbulkan senyum bagi para pembaca Injil Matius. ${ }^{62}$ Tambahan waktu mungkin akan memampukan dia membayar sebagian kecil dari hutangnya; tetapi mengatakan bahwa dia akan membayar segala hutangnya hanya menunjukkan sebuah keputusasaan yang konyol!

Potensi humor ketiga dalam perikop ini muncul dalam prolog perumpamaan ini. Penolakan Yesus terhadap angka yang diajukan Petrus bukan tidak mungkin menghasilkan ilustrasi yang humoris. Seperti yang disebutkan sebelumnya, ketika berbicara mengenai kuantitas pengampunan, angka yang disodorkan Petrus kepada Yesus-tujuh kali-sebenarnya merupakan angka yang cukup fantastis. Pertanyaannya mengapa Petrus harus mengajukan angka tujuh? Menilik penggambaran karakter Petrus yang cenderung arogan (misal: Matius 16:22-23; 26:33-35; Yohanes 13:6-10), bukan tidak mungkin Petrus menyebut angka yang fantastis ini untuk mendapatkan pujian dari Yesus atau setidaknya

\footnotetext{
${ }^{62}$ Luz, Matthew, 472. Penekanan asli. Band. juga France, The Gospel of Matthew, 706. Penempatan $\pi \alpha ́ v \tau \alpha$ dalam permintaan hamba ini nampaknya bertujuan memberi penekanan tentang absurditas permintaannya.
} 
menunjukkan bahwa dirinya hebat. Lagipula, bila memang Petrus memang tulus ingin bertanya, maka dia bisa bertanya tanpa menyebut angka ("berapa kali aku harus mengampuni?") atau mulai dengan menyebut jumlah yang umum ("apakah cukup hanya tiga kali?").

Bila hipotesa ini diterima, maka penolakan Yesus terhadap usulan Petrus bisa jadi akan menghasilkan sebuah situasi yang komikal. Petrus datang ingin mendapatkan pujian dari Yesus atau setidaknya menunjukkan bahwa dia hebat, tetapi apa yang didapatnya justru penolakan dan sebuah jawaban lain yang membuat proposalnya jadi terlihat tidak ada apa-apanya. Ironi dalam adegan ini-ketika Petrus yang ingin dipuji dan terlihat hebat justru dibuat jadi terlihat konyol-bisa jadi akan memicu tawa bagi orang-orang yang melihat peristiwa itu maupun bagi pembaca pertama Matius. Meski demikian, harus diakui bahwa rekonstruksi ini sangat bergantung pada dua hal. Pertama, interpretasi ini mengasumsikan bahwa tradisi yang dicatat dalam $b$. Yoma $86 b$ merupakan tradisi yang awal. Kedua, interpretasi penulis yang mendeteksi adanya arogansi Petrus di sini diterima. ${ }^{63}$

\section{KESIMPULAN}

Dengan menggunakan definisi kerja yang mengaitkan humor dengan ide, gambar, teks, atau peristiwa yang ganjil dan aman atau non-serius (sehingga hal tersebut menjadi menyenangkan dan bisa dinikmati), penulis menyodorkan tiga potensi humor dalam perikop perumpamaan tentang pengampunan. Usulan pertama terkait dengan nominal hutang yang fantastis, usulan kedua soal permohonan si hamba yang tidak realistis, dan usulan ketiga

\footnotetext{
${ }^{63}$ Dalam taraf tertentu, penulis melihat bahwa Carson, Harrington, Mitch dan Sri juga menangkap ada tendensi arogansi dari Petrus. Lihat Carson, Matthew, 405; Daniel J. Harrington, The Gospel of Matthew (Sacra Pagina; Collegeville: Liturgical, 1991), 269; Mitch and Sri, The Gospel of Matthew, 234.
} 
merujuk pada situasi komik yang mungkin muncul dalam dialog antara Petrus dan Yesus di awal perikop. Harus diakui usulan ketiga memang tidak memiliki petunjuk humor sekuat dua yang pertama. Meski demikian, secara umum, penulis melihat bahwa tesis penulis-bahwa perikop ini mengandung potensi humor-sangat stabil. Bila demikian, ini berarti (1) ide bahwa Alkitab mengandung humor tidak boleh lagi dikesampingkan dan (2) tidak seperti yang diyakini Krisostomus, Yesus dalam Kitab Injil ternyata ditampilkan sebagai sosok yang humoris. Karena itu, melalui studi singkat ini, penulis berharap agar orang-orang maupun para pemikir Kristen bukan hanya lebih peka dengan eksistensi humor dalam Alkitab, ${ }^{64}$ tetapi juga lebih terbuka dengan kenyataan bahwa Yesus bukanlah pengajar yang serius, kering, dan kaku; sebaliknya, Ia adalah guru yang hidup, bijak, inspiratif, dan-tentu saja-humoris. ${ }^{65}$

\footnotetext{
${ }^{64}$ Untuk beberapa karya belakangan yang mencoba menunjukkan eksistensi humor dalam Alkitab, lihat Rognes, "Humor in the Bible"; Frank Ramirez, "A guy walks into a bar... A judge walks up to a king: Humor in the Hebrew Scriptures", in Brethren Life and Thought 57/1 (2012): 80-92; Terri Bednarz, "Status Disputes and Disparate Dicta: Humor Rhetoric in Luke 16:14-18", in Biblical Interpretation 21/3 (2013): 377-415; Iverson, "Incongruity, Humor, and Mark"; Steven C. Walker, Illuminating Humor of the Bible (Eugene, OR: Cascade, 2013).

${ }^{65}$ Untuk beberapa karya belakangan yang mencoba menunjukkan bahwa Yesus adalah sosok yang humoris, lihat Bruce W. Longenecker, "A Humorous Jesus? Orality, Structure and Characterisation in Luke 14:15-24, and Beyond,"Biblical Interpretation 16 (2008): 179-204; Kristianto, Jesus's Humor in the Antitheses, khususnya bab 3 .
} 


\section{DAFTAR RUJUKAN}

\section{BUKU DAN TAFSIRAN}

. Oxford Advanced American Dictionary.

Oxford: OUP, 2011.

Bednarz, Terri. Humor in the Gospels: A Sourcebook for the Study of Humor in the New Testament 1863-2014. Lanham: Lexington, 2015.

Blomberg, Craig L. Matthew. NAC; Nashville: Broadman \& Holman Publishers, 2001.

Brown, Raymond E. An Introduction to the New Testament. New York: Doubleday, 1997.

Capps, Donald. A Time to Laugh: the Religion of Humor. New York: Continuum, 2005.

Carroll, Noel. Humour: A Very Short Introduction. Oxford: OUP, 2014.

Carson, D. A. "Matthew", in Frank E. Gaebelein (ed.). EBC 8. Grand Rapids: Zondervan, 1984.

Charlesworth, James H. How Barisat Bellowed: Folklore, Humor, and Iconography in the Jewish Apocalypses and the Apocalypse of John. DSSCOL 3 (North Richland Hill, TX: Bibal, 1998).

Chesterton, Gilbert K. Heretics/Orthodoxy. Nashville: Thomas Nelson, 2000. 
Davies, W. D. and Dale C. Allison, A Critical and Exegetical Commentary on the Gospel According to Saint Matthew. ICC; 3 Vols; London/New York: T\&T Clark, 2004.

Flynn, Leslie B. Serve Him with Mirth: The Place of Humor in Christian Life. Grand Rapids: Zondervan, 1960.

France, R. T. The Gospel of Matthew. NICNT; Grand Rapids: Eerdmans, 2007.

Freedman, David Noel, ed. The Anchor Bible Dictionary 6 Vols. New York: Doubleday, 1996.

Goldstein, Jeffery H. and Paul E. McGhee. The Psychology of Humor: Theoretical Perspectives and Empirical Issues. New York: Academic, 1972.

Hagner, Donald A. Matthew 14-28. WBC 33b; Dallas: Word, 2002.

Halliwell, Stephen. Greek Laughter: A Study of Cultural Psychology from Homer to Early Christianity. Cambridge: CUP, 2008).

Harrington, Daniel J. The Gospel of Matthew. Sacra Pagina; Collegeville: Liturgical, 1991.

Hyers, Conrad. And God Created Laughter: the Bible as Divine Comedy. Atlanta: John Knox, 1987.

Jeremias, Joachim. The Sermon on the Mount. Philadelphia: Fortress, 1963. 
Jónsson, Jakob. Humor and Irony in the New Testament: Illuminated by Parallels in Talmud and Midrash. Leiden: Brill, 1965.

Keener, Craig S. The Gospel of Matthew: A Socio-Rhetorical Commentary. Grand Rapids: Eerdmans, 2009.

Luz, Ulrich. "Matthew", in Helmut Koester (ed.). Minneapolis: Augsburg, 2001.

Martin, Rod A. The Psychology of Humor: An Integrative Approach. Burlington: Elsevier, 2007.

Mitch, Curtis and Edward Sri, The Gospel of Matthew. Catholic Commentary on Sacred Scripture; Grand Rapids: Baker, 2010.

Morreall, John. Comic Relief: A Comprehensive Philosophy of Humor. Malden, Ma: Wiley-Blackwell, 2009.

Morris, Leon. The Gospel According to Matthew. PNTC; Grand Rapids/Leicester: Eerdmans/Apollos, 1992.

Mounce, Robert H. Matthew. NIBC: Peabody: Hendrickson, 1991.

Nolland, John. The Gospel of Matthew: A Commentary on the Greek Text. NIGTC; Grand Rapids/Carlisle: Eerdmans/Paternoster, 2005.

Osborne, Grant. Matthew. ZECNT; Grand Rapids: Zondervan, 2010.

Palmer, Earl F. The Humor of Jesus: Sources of Laughter in the Bible. Vancouver: Regent College, 2001. 
Radday, Yehuda T. and Athalya Brenner, eds. On Humour and Comic in the Hebrew Bible. Sheffield: Almond, 1990.

Raskin, Victor, ed. The Primer of Humor Research. Berlin: Mouton de Gruyter, 2008.

Turner, David L. Matthew. BECNT; Grand Rapids: Baker, 2008.

Walker, Steven C. Illuminating Humor of the Bible. Eugene, OR: Cascade, 2013.

\section{JURNAL DAN TESIS:}

Bednarz, Terri. Humor-neutics: Analyzing Humor and Humor Function in the Synoptic Gospels. Unpublished Ph.D dissertation, Texas Christian University, 2009.

. "Status Disputes and Disparate Dicta: Humor Rhetoric in Luke 16:14-18", in Biblical Interpretation 21/3 (2013): 377-415.

Harris, Henry F. "The Absence of Humor in Jesus", in Methodist Quarterly Review 57/3 (July 1908): 460-7.

Kelly Iverson, "Incongruity, Humor, and Mark: Performance and the Use of Laughter in the Second Gospel", in NTS 59 (2013):2-19.

Kristianto, Stefanus. Jesus's Humor in the Antitheses. Unpublished MTh thesis; Singapore: Trinity Theological College, 2017.

Longenecker, Bruce W. "A Humorous Jesus? Orality, Structure and Characterisation in Luke 14:15-24, and Beyond,"Biblical Interpretation 16 (2008): 179-204. 
Ramirez, Frank. "A guy walks into a bar... A judge walks up to a king: Humor in the Hebrew Scriptures," Brethren Life and Thought 57/1 (2012): 80-92.

Rogness, Michael. "Humor in the Bible", in Word \& World 32/2 (2012): 117-32.

Thoennes, Erik. "Laughing through Tears: Redemptive Role of Humor in in a Fallen World" in Presbyterion 33/2 (2007):7283.

Van Herden, Willie. "Why the Humour in the Bible Plays Hide and Seek with Us"in Social Identities 7/1 (2001):75-96.

\section{INTERNET:}

Talmud Babilonia: Yoma, bisa diakses secara daring dari https://www.sefaria.org/Yoma.86b?lang=bi

Yakub Tri Handoko, "Seminar Humor dalam Alkitab," rekaman pertama, diakses dari https://www.youtube.com/watch?v=7EkT5MN4obM\&t=68s

Krisostomus, Yohanes. The Homilies on the Statues to the People of Antioch, Homily XV, diakses secara daring dari http://www.newadvent.org/fathers/190115.htm.

Homilies on Matthew VI, diakses secara daring dari http://www.newadvent.org/fathers/200106.htm. 